-

\section{Appreciating \\ interconnectivity between habitats is key to blue carbon management}

We welcome the recent synthesis by Howard et al. (2017), which drew attention to the role of marine systems and natural carbon sequestration in the oceans as a fundamental aspect of climate-change mitigation. The importance of long-term carbon storage in marine habitats (ie "blue carbon") is rapidly gaining recognition (Figure 1a) and is increasingly a focus of national and international attempts to mitigate rising atmospheric emissions of carbon dioxide. However, effectively managing blue carbon requires an appreciation of the inherent connectivity between marine populations and habitats. More so than their terrestrial counterparts, marine ecosystems are "open", with high rates of transfer of energy, matter, genetic material, and species across regional seascapes (Kinlan and Gaines 2003). We suggest that policy frameworks, and the science underpinning them, should focus not only on carbon sink habitats but also on carbon source habitats, which play critical roles in marine carbon cycling and natural carbon sequestration in the oceans. Howard et al. (2017) concluded that certain habitats and taxa (eg kelp forests, large vertebrates) are "unimportant" in natural carbon sequestration, which we argue is an oversimplification that fails to account for not only the magnitude of carbon transfer between living components of the cycle but also the interconnectedness of the highly dynamic and open marine environment. Crucially, developing carbon budgets for habitats in isolation - without considering their connectivity and functioning as carbon "fixers", "donors", and "recipients" - is neither representative of marine ecosystems, nor a useful approach for prioritizing management. Here, we highlight the importance of carbon transfer between habitats, which is not currently recognized within policy frameworks, through two pertinent and widespread processes.

First, marine macroalgae generally exhibit very high rates of growth and primary productivity and are likely to play key roles in carbon cycling as fixers and donors. Kelp forests are particularly critical, given that they represent some of the most productive habitats on Earth and are geographically widespread across temperate regions in both hemispheres (Mann 1973; Teagle et al. 2017). As noted by Howard et al. (2017), kelp forests support high standing stocks of carbon (Smale et al. 2016; Figure 1b), but as the turnover of material is generally rapid they do not store carbon in situ at timescales relevant for sequestration (note: some kelp species persist for $>15$ years [Kain 1979], not the $\sim 1$ year stated by Howard et al. [2017]). Furthermore, the vast majority ( $>80 \%)$ of kelp-derived organic matter is typically exported from the kelp forest, rather than being consumed or remineralized within the source habitat (Krumhansl and Scheibling 2012). Kelp-derived matter may be transported many kilometers from its source (Vetter and Dayton 1998; Vanderklift and Wernberg 2008; Krause-Jensen and Duarte 2016) and eventually accumulate in blue carbon habitats with the capacity to bury organic matter, such as seagrass meadows and soft sediments (Hill et al. 2015; Krause-Jensen and Duarte 2016; Figure 1c). Allochthonous carbon (that is, organic matter that originated some distance from its current position) derived from kelp populations may be trapped, buried, and stored belowground, thereby substantially contributing to the amount of carbon fixed and stored in situ. Recent evidence suggests that macroalgae may be important carbon donors due to their high rates of biomass accumulation and export, extensive geographical distributions, and the chemical and physical properties of macroalgal detritus (Hill et al. 2015). Although more research is needed to quantify burial rates and residence times, kelp and other macroalgae play key roles in carbon sequestration (Krause-Jensen and Duarte 2016) and should be considered in the management and conservation of blue carbon ecosystem services.

Second, marine vertebrates play a major role in the removal of carbon from surface waters and its transfer to and sequestration in the deep ocean. Although some marine vertebrate biomass is recycled and respired over short timescales (Howard et al. 2017), once exported to the deep ocean it remains sequestered for 1000-year timescales. Mesopelagic fish respire $\sim 10 \%$ of global surface primary production at depth by feeding in shallow waters and migrating to deep water, accounting for $\sim 15 \%$ of total carbon export (reviewed by Drazen and Sutton 2017). Deep-sea demersal fish also sequester carbon by consuming vertically migrating plankton. On the UK-Irish continental margin alone, this mechanism prevents an estimated $3.5-6.2 \times 10^{5}$ metric tons of carbon per year $(\mathrm{t} C$ $\mathrm{yr}^{-1}$ ) from recycling back into the atmosphere (Trueman et al. 2014). Passive export occurs through the sinking of dead carcasses: whale detritus (Figure $1 \mathrm{~d}$ ) exports $2.7 \times 10^{5}$

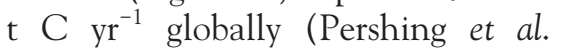
2010), and cumulative vertebrate carcass export accounts for $4-11 \%$ of particulate carbon flux to the deep sea (Higgs et al. 2014). The deposition of carcasses into deep-sea habitats markedly increases the organic carbon content of surrounding sediments and therefore represents a fundamental process for local carbon sequestration. This "biological pump" of carbon from surface waters to the deep ocean is currently operating at reduced efficiency because of anthropogenic changes to the size structure of marine vertebrate populations. Policies aimed at rebuilding stocks of marine vertebrates can therefore have a positive impact on carbon sequestration at a global scale and should be valued accordingly (eg Martin et al. 2016).

We commend Howard et al. (2017) for promoting the conservation of marine carbon stores as a promising 

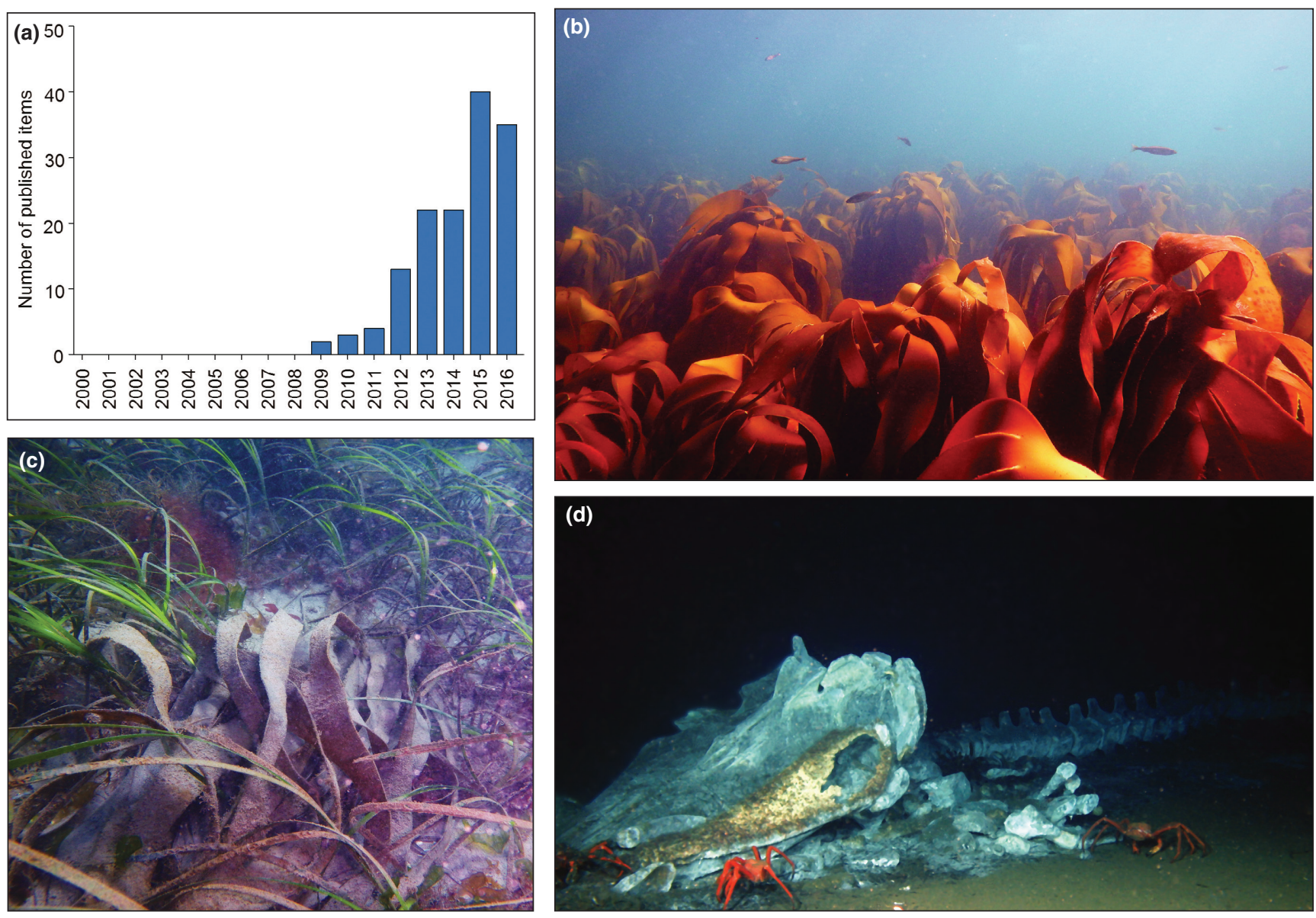

Figure 1. (a) The number of scientific articles focusing on blue carbon has greatly increased in recent years (publications per year with blue carbon in the title and pertaining to inshore carbon cycles; Google Scholar search conducted on 24 Feb 2016). (b) Kelp forests are very productive and represent extensive coastal vegetated habitats. (c) The majority of kelp-derived matter is exported and may accumulate within blue carbon recipient habitats such as seagrass meadows. (d) Sinking vertebrate carcasses represent an important flow of particulate carbon to deep-sea sedimentary habitats.

aspect of climate-change mitigation. We also appreciate that their review focused on carbon sink habitats, which fall within existing management and policy frameworks. We suggest, however, that scientists, managers, and policy makers should consider carbon source habitats as well as sinks in future assessments of the importance of marine systems in natural carbon sequestration. By managing and protecting effective and widespread carbon donors, such as kelp forests and large vertebrates, the magnitude of carbon capture and transfer, as well as the efficiency of assimilation into storage habitats, will be maintained or even enhanced. For example, carbon crediting schemes currently exclude allochthonous carbon from their evaluations, despite emerging evidence of the importance of externally sourced organic matter for natural carbon sequestration. As the wider understanding of coastal carbon cycling advances, policy frameworks such as the United Nations Framework Convention on Climate Change (UNFCCC) should evolve to incorporate processes that promote natural carbon sequestration by, for instance, acknowledging the role of carbon donors in crediting and management. More broadly, evaluating the role of marine systems in climate-change mitigation can be meaningful and effective only through a wider appreciation of the interconnectivity and interactions between marine habitats and taxa, rather than by adopting a simpler approach of carbon budgeting habitats in isolation in order to prioritize their management.
Dan A Smale ${ }^{1 *}$, Pippa J Moore ${ }^{2,3}$, Ana M Queirós ${ }^{4}$, Nicholas D Higgs ${ }^{5}$, and Michael T Burrows ${ }^{6}$

${ }^{1}$ Marine Biological Association of the United Kingdom, Plymouth, UK *(dansma@mba.ac.uk); Institute of Biological, Environmental and Rural Sciences, Aberystwyth University, Aberystwyth, UK; ${ }^{3}$ Centre for Marine Ecosystems Research, School of Natural Sciences, Edith Cowan University, Joondalup, Australia; ${ }^{4}$ Plymouth Marine Laboratory, Plymouth, UK;

${ }^{5}$ Marine Institute, Plymouth University, Plymouth, UK; ${ }^{6}$ Scottish Association for Marine Science, Dunbeg, UK

Drazen JC and Sutton TT. 2017. Dining in the deep: the feeding ecology of deep-sea fishes. Ann Rev Mar Sci 9: 337-66.

Higgs ND, Gates AR, and Jones DOB. 2014. Fish food in the deep sea: 
revisiting the role of large food-falls. PLoS ONE 9: e96016.

Hill R, Bellgrove A, Macreadie PI, et al. 2015. Can macroalgae contribute to blue carbon? An Australian perspective. Limnol Oceanogr 60: 1689_ 706.

Howard J, Sutton-Grier A, Herr D, et al. 2017. Clarifying the role of coastal and marine systems in climate mitigation. Front Ecol Environ 15: 42-50.

Kain JM. 1979. A view of the genus Laminaria. Oceanogr Mar Biol Ann Rev 17: 101-61.

Kinlan BP and Gaines SD. 2003. Propagule dispersal in marine and terrestrial environments: a community perspective. Ecology 84: 2007-20.

Krause-Jensen D and Duarte CM. 2016. Substantial role of macroalgae in marine carbon sequestration. Nature Geosci 9: 737-42.

Krumhansl K and Scheibling RE. 2012. Production and fate of kelp detritus. Mar Ecol-Prog Ser 467: 281-302.

Mann KH. 1973. Seaweeds: their productivity and strategy for growth. Science 182: 975-81.

Martin SL, Balance LT, and Groves T. 2016. An ecosystem services perspective for the Oceanic Eastern Tropical Pacific: commercial fisheries, carbon storage, recreational fishing, and biodiversity. Front Mar Sci 3: 50.

Pershing AJ, Christensen LB, Record NR, et al. 2010. The impact of whaling on the ocean carbon cycle: why bigger was better. PLoS ONE 5: e12444.

Smale DA, Burrows MT, Evans AJ, et al. 2016. Linking environmental variables with regional-scale variability in ecological structure and standing stock of carbon within kelp forests in the United Kingdom. Mar Ecol-Prog Ser 542: 79-95.

Teagle H, Hawkins SJ, Moore PJ, and Smale DA. 2017. The role of kelp species as biogenic habitat formers in coastal marine ecosystems. J Exp Mar Biol Ecol 492: 81-98.

Trueman CN, Johnston G, O'Hea B, and MacKenzie KM. 2014. Trophic interactions of fish communities at midwater depths enhance long-term carbon storage and benthic production on continental slopes. P Roy Soc B-Biol Sci 281: 20140669.

Vanderklift MA and Wernberg T. 2008. Detached kelps from distant sources are a food subsidy for sea urchins. Oecologia 157: 327-35.

Vetter EW and Dayton PK. 1998. Macrofaunal communities within and adjacent to a detritus-rich submarine canyon system. Deep-Sea Res Pt II 45: 25-54.

doi:10.1002/fee. 1765
兴

\section{Coastal wetlands are the best marine carbon sink for climate mitigation}

We thank Smale and colleagues for their comments on our recent paper, for highlighting areas where additional research is warranted, and for their overview of the recent literature that was not available when we submitted our manuscript. It is encouraging to see new papers being published that are helping scientists better understand carbon cycles in coastal and marine ecosystems and their important dynamics.

Our paper evaluated how coastal and marine ecosystems can be used for climate mitigation within the current international policy context, including existing mechanisms related to carbon accounting. To that end, we focused on those ecosystems that can be managed for permanent carbon sequestration and storage at globally relevant scales and that potentially contribute to countries' national greenhouse-gas (GHG) emissions reduction pledges. Oceanic and coastal carbon cycles and dynamics, while critically important for understanding climate change and its impacts, are not currently the focus of such policies. Rather, mitigation policy concentrates on human actions that change - either by increasing or by decreasing - carbon sequestration and storage beyond the naturally occurring "baseline" condition of the carbon cycle, and by so doing either accelerate or slow climate change. So, while many ecosystems are vital for moving carbon through the carbon cycle and for burying carbon in the deep ocean, these are not of explicit climate mitigation value because they do not provide additional carbon benefits (known as additionality) beyond the natural cycle, or baseline condition. For example, protecting a mangrove forest that is threatened by logging - where that logging would result in major losses of sequestered carbon - is a management activity that can have measurable impacts on current and future atmospheric carbon emissions. Similarly, restoring a degraded salt marsh and thereby improving its carbon sequestration capacity is a human action that directly affects long-term atmospheric carbon levels. Thus, these are the types of management activities that are relevant when countries are both (1) assessing their climate-change emissions and (2) determining the range of actions available for $\mathrm{GHG}$ emission reductions in order to meet climatechange mitigation goals.

To be included in the current climate-change mitigation policy framework (hereafter, "framework") and accounting mechanisms, not only must there be additional carbon benefits beyond the baseline carbon cycle conditions, but those benefits must also be quantifiable. Smale and colleagues suggest it is important to be "managing and protecting effective and widespread carbon donors" because this will increase "the magnitude of carbon capture and transfer". While this may be true, management actions in these donor ecosystems would need to be clearly distinguished from baseline conditions, and a great deal of science would be required to meet the burden of evidence it would take to incorporate these donor ecosystems into the framework. In reality, this burden of evidence would likely be too difficult or too costly an undertaking for many countries, which makes it difficult to include carbon from these donor ecosystems. Another hurdle for inclusion in climate mitigation policy is the need for the carbon management activity to fall within a country's jurisdiction. The current framework has been developed based on country contributions within country boundaries. The open ocean does not fit within the framework because it is neither owned nor managed by any one country. While we would support policy changes that would allow the open ocean to be included, we do not anticipate such a shift in ocean or 